\title{
Informal Social Support: A Collaborative Stress Management Initiative for Mothers of Cancer Children
}

\author{
Siham. M. Al- Momani ${ }^{1}$ \\ ${ }^{1}$ Department of Allied Medical Sciences, Al Balqa' Applied University, Zarka College, Jordan \\ Correspondence: Siham. M. Al- Momani, Department of Allied Medical Sciences, Al Balqa' Applied University, \\ Zarka, Jordan. Tel: 962-799-30-6030. E-mail: simomany@yahoo.com
}

Received: March 24, 2013

Accepted: April 16, 2013 Online Published: May 14, 2013

doi:10.5539/ijps.v5n2p19

URL: http://dx.doi.org/10.5539/ijps.v5n2p19

\begin{abstract}
Diagnosis of childhood cancer represents one of the most sever stressors for the children's mothers. There is limited evidence of research directed toward assisting mothers of cancer children to develop strategies to cope with the complex experiences associated with the diagnosis of their children at the time of the diagnosis, and before their reaction to stress recognized. The current study is a pilot project sought to investigate the potential of a new type of initiative based on the idea of providing the mothers of cancer children with informal social support, were the support initiated in collaboration between the academic and clinical staffs. The informal social support initiative program started at the time of child diagnosis before the patient and patient families requested or even the physician ordered.
\end{abstract}

Surveys results, along with discussion of the potential implications for reducing stress and anticipatory stress among mothers of cancer children by informal social support are presented.

Keywords: social support, informal social support, collaborative, initiative, stress, stress reactions, stress management, mothers of cancer children

\section{Introduction}

Even with the improvement in cancer treatment, and three out of four children diagnosed with a malignancy will survive their disease and treatment. Although, overall cancer death rates have declined $20 \%$ from their peak in 1991 (Greenlee et al, 2000., Siegel et al, 2013), still the diagnosis and treatment of child with cancer represents the start of a stressful and long-term process especially for the children's mothers (Kazak, 1998.,Barrera et al, 2004). Lindahl-Norberg et al (2005b) titled this stressful process as a process of psychological stress. Different psychologists have given different definitions to stress and stressors. Stressors broadly defined by Barling (1990) as situations or events that have the potential to affect the person health outcomes. Stress has been viewed by Chiang and Hunter (2004) as a complex and dynamic transaction between individuals and their environments. In the Wikipedia (2009) stress defined as a biological term for the consequences of the failure of a human or animal to respond appropriately to emotional or physical threats to the organism, whether actual or imagined. It includes a state of alarm and adrenaline production, short-term resistance as a coping mechanism, and exhaustion. Common stress symptoms include irritability, muscular tension, inability to concentrate and a variety of physical reactions, such as headaches and elevated heart rate (Wikipedia, 2009).

The diagnosis of childhood cancer represents the start of a stressful and long-term process especially for the children's mothers and it has been viewed as one of the most sever stressors that a parent can experience (Kazak, 1997). A period of substantial distress for parents, who report shock, emotional pain, and difficulty coping with the necessary procedures performed on their child, rumination, and high levels of information seeking accompanied by a sense of lack of control. The damage inflicted by stress is frequently mentioned in the literature. Barrera et al (2004) found that both mothers and fathers of children undergoing cancer treatment reported traumatic stress symptoms (PTSD) such as intrusive thoughts, physiologic arousal, and avoidance. When parents are confronted with a diagnosis of cancer in their child a process starts, referred to as psychological stress (Lindahl-Norberg, et al 2005b)

Studies of parental stress and stress reaction related to diagnosis and treatment of childhood cancer indicated that the stress reactions including uncertainty, anxiety, depressive symptoms, and the posttraumatic stress symptoms 
occur most frequently around the time of diagnosis and decrease over time (Santacroce, 2002; Yeh, 2002; Barrera et al., 2004; Chushieh S, SinTung H, \& YuanLiang S., 2012; Lindahl-Norberg, Lindblad, \& Boman, 2005b; Alderfer, M. A.,et al, 2005; Phipps, Long, Hudson, \& Rai, 2005; Tatjana K et al, 2012; Jantien Vrijmoet-Wiersma, C.M., et al, 2008). All what was mentioned from the signs of stress we recognized it from the mothers of cancer children who was admitted to the pediatric department, most of the mothers were crying, refused eating, nervous even with routine interpersonal communication, which was reflected on their admitted children, child starts crying when his/her mother's cry . Also some mothers have verbalized difficulties in meeting their family's requirements as looking after their other children who stayed at home alone. Funding the cancer children treatment it was another challenge for some families.

Although health care workers including nurses are aware of stress associated with diagnosis and treatment of child with cancer especially for the children's mothers and several research findings emphasized the importance of social support on the individual's adjustment, and the importance of providing content in advance for the development of coping strategies (Best et al, 2001; Bruce, 2006; Chiquelho et al, 2011; Cobb, 1976; Cohen, Sherrod \& Clark, 1986; Cutrona, Russell, \& Rose, 1986; Dockerty et al, 2000; Holahan \& Moos, 1985; Lindahl et al, 2006; O'Reilly, 1988; Salovey, 2000; Sarason et al., 1987; \& ChuShieh, S et al, 2012). There is limited evidence of research directed toward assisting mothers of cancer children to develop strategies to cope with the complex experiences associated with the diagnosis of their children at the time of the diagnosis, and before their reaction to stress recognized. This motivates us to start our social support initiative the concern of this study. Because, we found that there is a need to evaluate methodologies within the aggregate of mothers of cancer children to delimit the effects of informal social support in managing the stress experienced by the mothers of cancer children. Such methodologies can continue to be utilized in the health field practice at the national or even international level. So the current study is a pilot project sought to investigate the potential of a new type of initiative based on the idea of providing the mothers of cancer children with informal social support, were the support initiated in collaboration between the academic and clinical staffs. The informal social support initiative program started at the time of diagnosis, aimed to manage the stress and stress reactions among the mothers of cancer children, does not require additional time, staff, or costs compared with the potential risk of psychological problems the mothers of cancer children are exposed to, and it will be started before the patient and patient families requested or even the physician ordered.

\section{Theoretical Framework}

Cox (1978) transactional model of stress was used to guide this initiative in which stress is viewed as imbalance between the individual's perception of the demands of environment and the perception of his capability to meet the demands. The emphasis of the model is on the individual's cognitive appraisal of the potentially stressful situation and his perception of his ability to cope. If there is an imbalance between the perceived demands of the environment and the perception of the individual's capacity to meet the demands, stress occurs and physiological and psychological resources are mobilized to meet the environmental demands. The fulfillment of physiological and psychological needs is important in determining the individual's behavior (Cox, 1978). Having help and support from friends and family to mothers of cancer children has been shown to fulfill the physiological and psychological needs and improve mothers of cancer children adjustment to their children diagnosis and treatment (Speechley \& Noh, 1992).

Consistent with the transactional model, the ultimate goal of the initiative was to offer a comprehensive informal social support program involving many players, including peers, nursing students, educators, and clinical staff all providing support in advance to mothers of cancer children, in order to fulfill the physiological and psychological needs of the mothers of cancer children which would manage the stress and stress reactions of them.

Social support defined by (Dalgard, 1998; Wilsey \& Shear, 2007) as the potential of the network to provide help in situations when needed. House (1981) described four main categories of social support: emotional, appraisal, informational and instrumental. Emotional support generally comes from family and close friends and is the most commonly recognized form of social support. It includes empathy, concern, caring, love, and trust. Appraisal support involves transmission of information in the form of affirmation, feedback and social comparison. This information is often evaluative and can come from family, friends, co-workers, or community sources. Informational support includes advice, suggestions, or directives that assist the person to respond to personal or situational demands. Instrumental support is the most concrete direct form of social support, encompassing help in the form of money, time, in-kind assistance, and other explicit interventions on the person's behalf. Social support is closely related to the concept of a social network, or the ties to family, friends, neighbors, colleagues, and others of significance to the person (House, 1981). The operational definition of these 
four categories is shown in Table 1.

Table 1. Four general categories of social support provided to the participants (Operational definitions)

\begin{tabular}{|c|c|c|c|}
\hline \multicolumn{4}{|c|}{ Social Support } \\
\hline Category & & Form & Resources Persons \\
\hline \multirow[t]{6}{*}{ Emotional Support } & - & Empathy & \multirow{2}{*}{$\begin{array}{l}\text { Peers (Mothers of cancer } \\
\text { children) }\end{array}$} \\
\hline & - & Concern & \\
\hline & - & Caring & \multirow{2}{*}{$\begin{array}{l}\text { - Researcher (Faculty } \\
\text { member) }\end{array}$} \\
\hline & - & Love & \\
\hline & 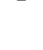 & Love & Nursing staff (Preceptors) \\
\hline & - & Irust & Nursing students \\
\hline \multirow{3}{*}{ Appraisal Support } & & ISSion of Information in the form of & \multirow{3}{*}{$\begin{array}{l}\text { Co-workers (Each up to } \\
\text { professional rules and } \\
\text { responsibilities. }\end{array}$} \\
\hline & - & Affirmation & \\
\hline & - & Feedback & \\
\hline \multirow[t]{3}{*}{ Informational Support } & - & Advice & \\
\hline & - & Suggestions & \\
\hline & $\begin{array}{l}- \\
\text { re }\end{array}$ & $\begin{array}{l}\text { Directives that assist the person to } \\
\text { to personal or situational demands }\end{array}$ & \\
\hline \multirow[t]{3}{*}{ Instrumental Support } & - & Money & \\
\hline & - & Time & \\
\hline & - & In-kind assistance & \\
\hline
\end{tabular}

Derived from (House, 1981)

Consistent with the social support framework, the ultimate goal of our initiative program was to relieve the cancer children mothers' stress and improving their adjustment to diagnosis and treatment of their children through providing them with a multidimensional collaborative informal social support were the support provided at the time of diagnosis even before the stress reactions recognized.

\section{Method}

\subsection{Study Hypotheses}

Although the main purpose of the informal social support initiative was to manage the stress among mothers of cancer children, the specific objectives of this study was to determine the degree to which the informal social support initiative program has on the stress response of mothers of cancer children, as well as the degree to which the program would meet with positive reactions from the participants mothers, therefore, this study hypothesized that:

1) Mothers had positive reactions toward the informal support initiative program as indicated by a survey data completed by them in order to determine their satisfaction of the initiative program components.

2) Mothers stress and stress reactions had been controlled or relieved after their participation in the informal social support initiative program as measured by Arabic-Language Modified Version of Beck Depression Inventory-1.

\subsection{Study Design}

To evaluate the initiative effectiveness a pre-test/post-test experimental and control group design (Polit, Beck \& Hungler, 2005) were utilized, a stress level assessment survey using Arabic - Language Modified Version of Beck Depression Inventory - 1(BDI-1) carried out to assess the level of stress experienced by the mothers before the mothers participated in the initiative program, and giving the same survey at any time the child being for discharge or transferred. Mothers enrolled in the initiative program were also asked to complete the Participants Reaction Index (Appendix A) at the time of discharge. 


\subsection{Population}

The eligible population for this study was all the mothers of cancer children, able to read and write in Arabic language, and their children had been admitted to the hospital and diagnosed as a case of cancer, with no more than 24 hours of time elapsed since diagnosis.

\subsection{Sample}

Convenience sampling procedure was used to obtain the larger number of mothers, anticipated that all the participants would be mothers, because this is one of the hospital policies which permit only for the child mother to stay with the child during the child admission, and in case that the mother's has any excuses and could not stay with the child another female of the child family members allowed to stay with the child. Each mother who participated in the initiative program within the first 24 hours of her child diagnosis, and her child admitted to the hospital pediatric unit at the time the initiative implemented and completely committed to the initiative program was assigned to the experimental group. Mother agreed to participate but did not committed to the initiative program was assigned to the control group. Participants were recruited to obtain an equal number in each group. A total of 120 mothers were approached, and 80 (67\%) agreed to participate. Exclusion criteria for participation include data which permitted to be reached, and could be gathered from the child medical file either from the demographic or family history information included (a) mothers who had been referred previously for formal psychosocial support, (b) mother working in the health care professionals, and (c) illiterate or non-Arabic-speaking mothers. Subsequent to exclusion of mothers based on the mentioned exclusion criteria's. The sample includes forty mothers in the control group and forty mothers in the experimental group. The demographic and medical variables of the groups are presented in Table 2.

Table 2. Demographic and medical variables

\begin{tabular}{|c|c|c|c|c|}
\hline \multirow[t]{2}{*}{ Variable } & \multicolumn{2}{|l|}{$\begin{array}{l}\text { Experimental group } \\
(\mathrm{N}=40)\end{array}$} & \multicolumn{2}{|l|}{$\begin{array}{l}\text { Control group } \\
(\mathrm{N}=40)\end{array}$} \\
\hline & Mean & $\mathrm{SD}$ & Mean & $\mathrm{SD}$ \\
\hline \multicolumn{5}{|l|}{ Mothers } \\
\hline Age & 28 & \pm 4.2 & 30 & \pm 6.3 \\
\hline Annual household income & $6000 \mathrm{JDs}=7800 \$$ & \pm 1000 & $6000 \mathrm{JDs}=7800 \$$ & \pm 1000 \\
\hline Education & $\mathrm{n}$ & $\%$ & $\mathrm{n}$ & $\%$ \\
\hline Postsecondary & 10 & $25 \%$ & 12 & $30 \%$ \\
\hline College graduates & 15 & $37.5 \%$ & 10 & $25 \%$ \\
\hline University graduates & 15 & $37.5 \%$ & 18 & $45 \%$ \\
\hline \multicolumn{5}{|l|}{ Occupation } \\
\hline House wife & 25 & $62.5 \%$ & 22 & $55 \%$ \\
\hline School teacher & 15 & $37.5 \%$ & 18 & $45 \%$ \\
\hline \multicolumn{5}{|l|}{ Living } \\
\hline With or near to an Extended family & 25 & $62.5 \%$ & 30 & $75 \%$ \\
\hline Away from their families & 15 & $37.5 \%$ & 10 & $25 \%$ \\
\hline \multicolumn{5}{|l|}{ Children } \\
\hline Age & $5 \mathrm{yrs}$ & \pm 3.5 & $5 y r s$ & \pm 4 \\
\hline \multicolumn{5}{|l|}{ Gender } \\
\hline Male & 19 & $47.5 \%$ & 15 & $37.5 \%$ \\
\hline Female & 21 & $52.5 \%$ & 25 & $62.5 \%$ \\
\hline Medical insurance & 40 & $100 \%$ & 40 & $100 \%$ \\
\hline Time from diagnosis & \multicolumn{2}{|l|}{ Recent 1 day-2 wks } & \multicolumn{2}{|l|}{$1-12$ months } \\
\hline Type of cancer & & & & \\
\hline
\end{tabular}




\begin{tabular}{llllr}
\hline Leukemia & 27 & $67.5 \%$ & 30 & $75 \%$ \\
Lymphoma & 5 & $12.5 \%$ & 4 & $10 \%$ \\
Solid tumor & 8 & $20 \%$ & 6 & $15 \%$ \\
Treatment status & All on active treatment & All on active treatment \\
& $(<2 \mathrm{Wks})$ & \multicolumn{2}{c}{$(1-12$ months $)$} \\
\hline
\end{tabular}

\subsection{Setting}

Pediatric unit located in a general teaching hospital with an 85 - bed inpatient. The unit receives the child who is less than 10 years old during the phase of diagnosis and starting the course of cancer treatment, and then the child has to be transferred to a specialized cancer treatment hospital the waiting for transfer varies between two days-to-two weeks or more periods after the diagnosis of the case, which depend on the availability of beds in the specialized cancer center, medical insurance system and fund, regardless of the conditions treatment started as early as the time of the diagnosis.

\subsection{Instruments}

\subsubsection{Demographic Questionnaire}

Mothers indicated their age, educational status, marital status, occupation, living condition (living separately or with their extended families), and total income of the family, number of family members and age of each family member, medical insurance, and their child's age, gender, order of the child among other children of the family. The questionnaire included three items to be filled by the researcher these are length of time since diagnosis, type of cancer, and treatment status. The socio-demographic and disease related characteristics of the mothers and their children are presented in Table 2 .

\subsubsection{Arabic - Language Modified Version of Beck Depression Inventory - 1(BDI-1)}

The original Beck Depression Inventory-1(BDI-1), developed by Beck et al (1961) is a valid and reliable, 21-item self-report measure of depressive symptoms (Beck, et al 1961). Respondents rated on a four point scale ranging from 0 to 3 the intensity of symptoms. Sum scores 0-9 indicates minimal depression, 10-18 indicates mild depression, 19-29 indicates moderate depression, and 30-63 indicates sever depression. Taking into account the social and cultural characteristics of the Arabic population, the BDI-1 was revised and modified by (Abohejleh, N., \& Hamdi, N, presented in Sarhan, W. et al 2001). The Arabic-Language Modified Version of Depression Inventory is an 18- item self-report measure of depressive symptoms. Respondents rated on a 3-point scale ranging from 0 to 2 the severity of symptoms? Sum scores $<9=$ normal status, $10-18=$ mild level, $19-27=$ moderate level, and $>28=$ sever level of depression. The validity and reliability of the modified Arabic version of the scale has been confirmed (Sarhan, W. et al 2001).In this study, internal reliability for the total scale was .86 . The alpha coefficient was .84 by control group report and .88 by experimental group report.

\subsubsection{Participants Satisfaction Index}

The participants' satisfaction index is a 13 - items survey derived from the work of (Kirkpatrick, 1978). The index developed by the researcher to determine the participant reaction to and satisfaction of the informal social support initiative. Each question evaluates the participant satisfaction of one of the initiative program components which were planned to cover one of the four types of social support (Emotional, Appraisal, Informational and Instrumental). Participant's mother was asked to put on a continuum varies from $0-100 \%$ her opinion and view on the value of each component of the program to her during the period of her child admission. At the end of the survey participants were asked to write their comments on the program. Index was pilot-tested for clarity of presentation and content among a random population of non-hospitalized persons (See Appendix A for a copy of the Participants Satisfaction Index).

\subsection{Procedure}

After the initiative program reviewed and approved by the Institutional Review Board, six steps were followed in implementing the initiative program:

A. The mother of newly diagnosed child was visited by the researcher within the first 24 hours of the child diagnosis. Importance of informal social support at this time period discussed with the mother.

B. Mother's received the initiative program plan and were asked to participate in the program.

C. Mothers who agreed to participate signed a consent form insure the anonymity and the liability of continue or 
stop the procedures according to the mother's preference, and received the survey questionnaire which include the Demographic Questionnaire and Arabic - Language Modified Version of Beck Depression Inventory 1 (BDI-1) to be returned within two hours.

D. Mothers who returned the survey questionnaire received the initiative brochure. On the first part of the brochure definition of stress, possible sources of stress, normative and adaptive character of stress and the importance of fulfilling the physiological and psychological needs in determining the individual's behavior as viewed by Cox (1978) were mentioned. The second part of the brochure includes definition of social support derived from (Wilsey \& Shear, 2007) and the four types of social support as identified by (House, 1981). On the third part four stress management and relieving methods which include: Breathing exercises, Balanced diet, Time management and Power naps (Scott, E., 2009) were explained. The fourth part of the brochure referral process of the child to specialized cancer center was outlined. Finally community resources that can help cancer children and their families were listed. Brochure was pilot-tested for clarity of presentation and content among a random population of non-hospitalized persons.

E. Mothers invited to attend the planned meeting. Meeting scheduled for one hour daily 1-2 pm (During this time period the child expected to have a nap sleep after they received their treatment and lunch). The researcher, who was an educator and experienced in the teaching learning strategies, conducted all of the meeting. Meeting has a simple format (See Appendix B).

F. Mothers enrolled in the initiative program were asked to complete the Participants Satisfaction Index two weeks of their enrollments or at the time of being discharged. Subjects should attend at least five planned meeting before being permitted to fill the participants' reaction index.

All mothers of cancer children regardless of their agreement to participate in the initiative program or not were provided with stress management education brochure, permitted to attend the meeting scheduled for mothers of cancer children and shared the planned support group discussion.

\subsubsection{Support Group Discussion}

In the discussions which were facilitated by the researcher, participants were guided to focus on the challenges which faced them during their recent experience of being a mother of a child diagnosed with cancer. Krueger \& Casey (2000) emphasized the use of group interaction in a relatively naturalistic peer setting to generate data. Encouraging participants to articulate, clarify, challenge and respond to each other's accounts of their experiences, has the potential to reveal a shared language and a common frame of reference. At the end of each discussion key ideas derived from the discussion were identified and verified by participants as a reasonable summary of the group discussion (Krueger \& Casey, 2000). To ensure group size was manageable in terms of group participation and help the nurse preceptors and associate nursing students collaboration nurse preceptors and associate nursing students were allowed to attend the meeting as observers.

\subsubsection{Health Care Workers Collaboration}

The chairman of the department and the nurse manager were informed of the initiative program. The unit manager identified the senior preceptor to be our liaison with the patients, preceptors, and staff. Collaboration with the initiative program was one means of fulfilling the preceptors and staff roles, which served as an incentive for participation. Also participation of the nursing students in the initiative program was one means of fulfilling the advanced nursing course objectives - a required last-semester nursing program requirement, and served as an incentive for participation. All nurse preceptors and associate nursing students were informed, oriented, and received the initiative plan at a pre planned meeting, and were asked to facilitate the initiative program through their day-to-day assigned work and practice.

\subsection{Data Collection/Analysis}

Participants' mothers' satisfaction of the initiative program was determined by completion of a Participant Satisfaction Index two weeks of their enrollments and/or at the time of being discharged, subjects should attend at least five planned meeting before completing the participants' satisfaction index. Level of stress experienced by mothers was evaluated using Arabic - Language Modified Version of Beck Depression Inventory - 1(BDI-1). Pre-intervention a covering letter explain the purpose of the assessment followed by the demographic questionnaire and Arabic-Language Modified Version of Beck Depression Inventory -I (BDI-I) was attached together to be filled at the same time in the baseline assessment. The pre-intervention (baseline) reading for experimental and control group was within the first 24 hours of the child diagnosis, and before the mother enrolled with the initiative program. Follow-up visits to keep in contact with the children and their mothers, and to arrange for post-intervention (follow-up) reading for experimental and control group during their out patients 
clinic appointments at least one month from (baseline) reading were made. Participating mothers both from the experimental and control group were revisited and asked to fill the Arabic - Language Modified Version of Beck Depression Inventory - 1(BDI-1). The justification for these time frames came from the diagnostic criteria for PTSD which required that individuals be at least 1 month past the traumatic event (American Psychiatric Association, 1994), and the time constraints on the academic course completion. The data were analyzed with SPSS statistical package. Descriptive statistics were also examined. An alpha level of 0.05 was used for all statistical tests.

\section{Results}

The first hypothesis of this study was "Mothers had positive reactions toward the informal support initiative program as indicated by a survey data completed by them in order to determine their satisfaction of the initiative program components". This hypothesis was addressed by reviewing and summarizing participant responses to participants' reaction index survey. Overall, participants' ratings of the initiative program components were $88 \%$. On average, $90 \%$ of the respondents provided rating of $85-95 \%$ across all items. Means were calculated for each item. Results presented in Table 3 show that the help provided by the nursing students (Taking care of the child while mother's leave to her home) was rated as the highest favorable part of the social support program with a rate of $100 \%$ by all of the respondents. The other most favorable components as rated by respondents' were first phase stress assessment survey using Arabic-Language Modified Version of Beck Depression Inventory -I (BDI-I), brochure specially the parts which cover the Stress management strategies, Referral process outline, and the Community resources list. Meeting specially the part of discussing challenges, demonstrating stress management strategies, and the program coordinator approach was highly rated by respondents with a mean rate of $90 \%$. The least favorable component of the program as rated by respondents with a mean of $70 \%$ was the second phase stress assessment survey using Arabic-Language Modified Version of Beck Depression Inventory. The Participant Satisfaction Index also elicited participant's comments on the program. A content analysis of 202 comments provided by the respondents revealed eight categories (five positive and three negative). Table 4 shows the comments and their associated number of responses. The second hypothesis of this study was "Mothers stress and stress reactions had been controlled or relieved after their participation in the informal social support initiative program as measured by Arabic-Language Modified Version of Beck Depression Inventory-1". Data collected were analyzed using SPSS to ascertain significant differences within each group and between the experimental and control groups. The SPSS values were not statistically significant, independently of the type of comparison made. None of the demographic/ child illness variables were significantly correlated to mother's stress symptoms. Table 5 shows both groups result in the two surveys. The experimental group mean Modified BDI-1 in phase one and phase two $(\mathrm{M}=7.97, \mathrm{SD} 4.19$, and $\mathrm{M}=7.70$, SD 4.21) respectively. More than $67.5 \%$ in the first and second surveys scored in the normal level; while the rest $33 \%$ scored in the mild level of stress. The control group mean Modified BDI-1 in phase one ( $M=8.87$, SD 6.42), and ( $M=7.85$, SD 5.02) in phase two. $60 \%$ scored in the normal range of stress in the two surveys; $32.5 \%$ scored in the mild level, and $7.5 \%$ in the moderate level of stress in the first survey. $35 \%$ of the control group scored in the mild level and $5 \%$ in the moderate level of stress in the second survey.

Table 3. Participants' opinion and view on the value of each of the initiative program component

\begin{tabular}{llc}
\hline & Participant's Reaction Index (N=40) & Mean (\%) \\
\hline 1 & Pre-Program Survey Questionnaire & $90 \%$ \\
2 & Brochure & \\
& - Introduction & $89 \%$ \\
& - Stress management strategies & $90 \%$ \\
& - Social Support and it's types & $88 \%$ \\
- Referral process outline & $90 \%$ \\
- Community resources list & $90 \%$ \\
3 & Meeting & \\
& - Introduction & $88 \%$ \\
- Discussing challenges & $90 \%$ \\
\hline
\end{tabular}


- Demonstrating stress management strategies $\quad 90 \%$

4 Help provided by the nursing students $\quad 100 \%$

(Taking care of your child while you leave to your home) as an example

5 Post-Program Survey Questionnaire $\quad 70 \%$

6 Reaction index ( The survey you are filling $88 \%$ now)

7 Program Coordinator Approach $\quad 90 \%$

Table 4. Summary of participants mothers comments about the social support program and their associated number of responses

\begin{tabular}{clc}
\hline No\# & \multicolumn{1}{c}{ Type of Comments } & \multicolumn{1}{c}{$\begin{array}{c}\text { Number of } \\
\text { responses }\end{array}$} \\
\hline Category & \multicolumn{1}{c}{ Positive } \\
1 & The program was very important and beneficial & 40 \\
2 & Information gained were helpful & 35 \\
3 & Demonstrating the stress management strategies & 30 \\
& Were beneficial & 30 \\
4 & Information and skills gained could be used in the future & 40 \\
Category & Comfortable discussing the challenges & \\
1 & Still my child is ill & 5 \\
2 & More information needed & 10 \\
3 & Time not enough & 12 \\
\hline
\end{tabular}

Table 5. Stress level among the experimental and control group

\begin{tabular}{|c|c|c|c|c|c|c|c|}
\hline \multicolumn{4}{|c|}{ Phase 1} & & \multicolumn{3}{|c|}{ Phase 2} \\
\hline & & $\mathrm{N} \#$ & Mean & $\mathrm{SD}$ & $\mathrm{N \#}$ & Mean & $\mathrm{SD}$ \\
\hline \multicolumn{2}{|c|}{ Experimental group } & 40 & 7.97 & 4.19 & 40 & 7.70 & 4.21 \\
\hline \multicolumn{2}{|l|}{ Control group } & 40 & 8.87 & 6.42 & 40 & 7.85 & 5.02 \\
\hline \multicolumn{2}{|c|}{ Severity of stress symptoms } & Normal & Mild & \multicolumn{2}{|c|}{ Moderate level } & \multicolumn{2}{|c|}{ Sever level } \\
\hline \multirow{2}{*}{\multicolumn{2}{|c|}{ No\# of cases }} & \multirow[t]{2}{*}{$<9$} & level & \multirow{2}{*}{\multicolumn{2}{|c|}{$19-27$}} & \multirow{2}{*}{\multicolumn{2}{|c|}{$>28$}} \\
\hline & & & $10-18$ & & & & \\
\hline $\begin{array}{l}\text { Experimental } \\
\text { Group }\end{array}$ & Phase 1 & 27 & 13 & \multicolumn{2}{|c|}{0} & \multicolumn{2}{|c|}{0} \\
\hline $\begin{array}{l}\text { Experimental } \\
\text { Group }\end{array}$ & Phase 2 & 27 & 13 & \multicolumn{2}{|c|}{0} & \multicolumn{2}{|c|}{0} \\
\hline Control Group & Phase 1 & 24 & 13 & \multicolumn{2}{|c|}{3} & \multicolumn{2}{|c|}{0} \\
\hline Control Group & Phase 2 & 24 & 14 & \multicolumn{2}{|c|}{2} & \multicolumn{2}{|c|}{0} \\
\hline
\end{tabular}

Note. Number appears in each cell present the number of cases mach the level of stress at that column.

\section{Discussion}

The results of this study were evaluated using the first and fourth levels of Kirkpatrick, S. Kirkpatrick, S. (1994) evaluating training programs: the four levels include reactions, learning, behavior, and results. Reactions, the 
first level of evaluating training program, relates to learner's satisfaction of the training program. Participants, ratings of the initiative program components and positive comments provide evidence to the potential value of the initiative program components. The study found as clarified from the mothers' comments and reactions to the initiative program components that the initiative was beneficial for the mothers of the cancer children. The study findings support the findings and recommendations provided by Baron, Cutrona, Hicklin, Russell, \& Lubaroff (1990), when they conclude that if the immediate family members or relatives are not available to help during caring for cancer patients outside help by health care workers as nurses, counselors, or social workers should be immediately given. Also, rating the help provided by the nursing students (Taking care of the child while mother's leave to her home) as the highest favorable part of the social support program with a rate of $100 \%$ by all of the respondents support the work of House (1981) when he identified the Instrumental support encompassing help in the form of in-kind assistance, and other explicit interventions on the person's behalf as the most concrete direct form of social support. The data provided important information about the most important components of the program as perceived by the participants. Kirkpatrick, S. (1994) fourth level of training programs evaluation consists of the result, this had been evaluated through the quasi-experimental and control group pre-post evaluation. Although, if we look to the individual cases of experimental and control group we found experimental group reported the lowest level of stress, they did not differ significantly from the control group. This finding supports the findings of (Barakat et al., 1997 \& Brown, Madan-Swain, \& Lambert, 2003) who confirm that the level of posttraumatic stress in the parents of cancer children, particularly their mothers was relatively low. Also, the findings of this study provide evidence to the potential value of the informal social support if the support provided immediately at the time of diagnosis, which support the findings of (Barrera, M. et al., 2004) and the recent work of (ChuShieh, S., SinTung, H., \& YuanLiang, S., 2012), and the potential value of the social support on promoting the mothers perceived ability of them selves and their diseased children which might inflect positively on their motivation and indirectly they will communicate these to their children, which support the work of (Archambault, I., Eccles, J. S., \& Vida, M. N., 2010). According to Archambault \& Vida (2010) early childhood professionals promote high expectations with parents, families and other professionals, and encourage families to communicate these to their children, as we accept the health team members especially the initiative team are directly involved with the children motivation and achievements during their hospitalization.

\section{Conclusion}

The work of this study was based on the assumption that "providing mothers of cancer children with informal social support at the time of their children diagnosis will help in managing their stress and stress reactions". This initiative was evaluated using Kirkpatrick's first and fourth levels of evaluating training programs. Reaction of the participants and their positive comments indicate that the program provide a sensible benefit to the participants. Findings of this study can potentially provide valuable initial evidence about issues related informal social support which should be provided to parents especially mothers of cancer children, and all mothers of hospitalized children.

Recognizing that the program does not represent any increase in the demands on the resources, In fact the program can have a beneficial effect for the staff as a part for achieving the incentives requirements, and for the nursing students through their practicing in order to achieve their learning objective in working as a change agent which is one of their curriculum objectives. Therefore, continuo in implementing the program as a continuous part of the collaborative activities of the nursing staff and the college faculty after filling the prerequisites administrative agreement, and to include all the admitted patient families at the practice area of the nursing students. Further longitudinal follow up study for the experimental group to measure the sustainable benefit of the program on the mothers could be done. Respecting the nursing students' facilitation of the program a study to evaluate the nursing students perception of the program could be carried out.

The limitations of the study include the small sample, the purposive convenience sample selection, and the self report surveys which could prohibit the generalization of the study findings. Validity and reliability of the results could be higher if a mixed method for evaluation of the mothers' stress reaction pr and post implementing the informal social support as assessment of the mothers' through observational tool was used.

The result of this study illustrates the need to examine carefully the sources of stress for mothers of cancer children and all parents of hospitalized children. Hospital related stressors need to be addressed by nursing professionals from the perspective that there may be ways of reducing the hospitalized child mother's stress through emotional support and giving specific information about the diagnostic procedures has to be done for her child. Lastly, faculty members in nursing colleges need to consider way in which they might contribute to affect positive evidence based change in clinical settings. 


\section{Acknowledgements}

The author wishes to thanks the sample both experimental and control group, health care workers, and the nursing students for their participation and collaboration in the initiative program.

\section{References}

Alderfer, M. A., Cnaan, A., Annunziato, R. A., \& Kazak, A. E. (2005). Patterns of Posttraumatic Stress Symptoms in Parents of Childhood Cancer Survivors. Journal of Family Psychology, 19(3), 430-440. http://dx.doi.org/10.1037/0893-3200.19.3.430

American Psychiatric Association. (2000). Diagnostic and Statistical Manual of Mental Disorders (4th ed., p. 828). Washington, DC. American Psychiatric Association.

Archambault, I., Eccles, J. S., \& Vida, M. N. (2010). Ability self-concepts and subjective value in literacy: Joint trajectories from grades 1 through 12. Journal of Educational Psychology, 102(4), 804-816. http://dx.doi.org/10.1037/a0021075

Barakat, L. P., Kazak, A. E., Meadows, A. T., Casey, R., Meeske, K., \& Stuber, M. L. (1997). Families surviving childhood cancer: A comparison of posttraumatic stress symptoms with families of healthy children. Journal of Pediatric Psychology, 22, 843-859. http://dx.doi.org/10.1093/jpepsy/22.6.843

Barling, J. (1990). Employment, stress and family functioning. New York: John Wiley \& Sons.

Baron, R. S., Cutrona, C. E., Hicklin, D., Russell, D. W., \& Lubaroff, D. M. (1990). Social support and immune function among spouses of cancer patients. Journal of Personality and Social Psychology, 59, 344-352. http://dx.doi.org/10.10370022-3514.59.2.344

Barrera, M., D'Agostino, N. M., \& Gibson, J. Gilbert, T., Weksberg, R., \& Malkin, D. (2004). Predictors and mediators of psychological adjustment in mothers of children diagnosed with cancer. Journal of Psycho-oncology, 13(9), 630-641. http://dx.doi.org/10.1002/ pon.765

Best, M., Streisand, R., Catania, L., \& Kazak, A. E. (2001). Parental distress during pediatric leukemia and parental posttraumatic stress symptoms after treatment ends. Journal of Pediatric Psychology, 26(5), 299-307. http://dx.doi.org/10.1093/jpepsy/ 26.3.155

Bourne, L. E., \& Ekstrand, B. R. (1982). Psychology: Its principles and meanings (4th ed.). New York: Rinehart and Winston, ISBN 0030596882.

Brown, R. T., Madan-Swain, A., \& Lambert, R. (2003). Posttraumatic stress symptoms in adolescent survivors of childhood cancer and their mothers. Journal of Traumatic Stress, 16, 309-318. http://dx.doi.org/10.1023/A:1024465415620

Bruce, M. (2006). A Systematic and conceptual review of posttraumatic stress in childhood cancer survivors and their parents. Clinical Psychology Review, 26(3), 233-256. http://dx.doi.org/10.1016/j.cpr.2005.10.002.

Chiang, L., Hunter, C. D., \& Yeh, C. J. (2004). Coping attitudes, sources, and practices among Black and Latino college students. Adolescence, 39(156), 793-815.

Chiquelho, R., Neves, S., Mendes, A., Relvas, A. P., \& Sousa, L. (2011). ProFamilies: A psycho-educational multi-family group intervention for cancer patients and their families. Journal of Cancer Care, 20(3), 337-344. http://dx.doi.org/10.1111/j.1365-2354.2009.01154.x

ChuShieh, S., SinTung, H., \& YuanLiang, S. (2012). Social Support as Influencing Primary Family Caregiver Burden in Taiwanese Patients with Colorectal cancer. Journal of Nursing Scholarship. http://dx,doi.org/10.1111/1547-5069. 2012. 01453

Cobb, S. (1976). Social support as a moderator of life stress. Psychosomatic Medicine, 38(5), 300-313.

Cox, T. (1978). Stress (p. 18). Baltimore: University Park Press.

Cutrona, C. E. (1986). Behavioral manifestations of social support: A micro analytic investigation. Journal of Personality and Social Psychology, 51(1), 201-208. http://dx.doi.org/10.1037/0022-3514.51.1.201

Dalgard, O. S. (1998).Clarifying the social support theory-research linkage. Journal of Advnced Nursing, 27(6), 1231-1241. http://dx.doi.org/10.1046/j.1365-2648.1998.01231.x

Dockerty, J. D., Williams, S. M., McGee, R., \& Skegg, D. C. G. (2000). Impact of childhood cancer on the mental health of parents. Journal of Med and Pediatric Oncology, 35(5), 475-483. http://dx.doi.org/10.1002/1096-911X (20001101)35:5<475: AID-MPO6>3.0.CO:2-U 
Greenlee, R. T., Murray, T., Bolden, S., \& Wingo, P. A. (2000). Cancer Statistics. Journal for Clinicians, 50, 7-33.

Holahan, C. J., \& Moos, R. H. (1985). Life stress and health: Personality, coping and family support in stress $\begin{array}{llll}\text { resistance. Journal of Personality and Social Psychology, 49(3), } & \text { 739-747. }\end{array}$ http://dx.doi.org/10.1037/0022-3514.49.3.739

House, J. S. (1981). Work: Stress and Social Support. Addison Wesley.

Jantien Vrijmoet-Wiersma C, M., van Klink, J. M., Kolk, A. M., Koopman, H. M, et al. (2008). Assessment of parental psychological stress in pediatric cancer: A review. Journal of Pediatric Psychology, 33(7), 694-706. http://dx.doi.org/10.1093/jpepsy/jsn007

Kazak, A. E., \& Barakat, L. P. (1997). Brief report: Parenting stress and quality of life during treatment for childhood leukemia predicts child and parent adjustment after treatment ends. Journal of Pediatric Psychology, 22(5), 749-758. http://dx.doi.org/10.1093/jpepsy/22.5.749

Kazak, A., Alderfer, M., Rourke, M. T., Simms, S., Streisand, R., \& Grossman, J. R. (2004). Posttraumatic stress disorder (PTSD) and posttraumatic stress symptoms (PTSS) in families of adolescent childhood cancer survivors. Journal of Pediatric Psychology, 29, 211-219. http://dx.doi.org/10.1093/jpepsy/jsh022

Kazak, A. E., Boeving, C. A., \& Alderfer, M. A. (2005). Posttraumatic stress symptoms during treatment in parents of children with cancer. Journal of Clinical Oncology, 23(30), 7405-7410. http://dx.doi.org/ 10.1200/JCO.2005.09.110

Kirkpatric, D. L. (1978, September). EVALUATING IN-HOUSE TRAINING PROGRAMS: HOW TO PLAN AND IMPLEMENT A SUPERVISORY TRAINING PROGRAM-PART 5. Training and Development Journal, 6-9.

Kirkpatric, D. L. (1994). Evaluating training programs: The four levels. San Francisco: Berrett-Koehler.

Krueger R., \& Casey M. A. (2000). Focus groups. A Practical Guide for Applied Research. London: London Sage Publication.

Manne, S. L., Miller, D. L., \& Meyers P. (1996). Depressive symptoms among parents of diagnosed children with cancer: A 6-month follow-up study. Journal of Child Health Care, 25, 191-209. http://dx.doi.org/ $10.1207 / \mathrm{s} 15326888 \mathrm{chc} 2503 \_3$

Manne, S., DuHamel, K., \& Ostroff, J. (2004). Anxiety, depressive, and posttraumatic stress disorders among mothers of pediatric hematopoietic stem cell transplantation. Journal of Pediatrics, 113, 1700-1708. http://dx.doi.org/10.1542/peds.113.6.1700

Lindahl-Norberg, A., Lindblad, F., \& Boman, K. K. (2005b). Parental traumatic stress during and after paediatric cancer treatment. Acta Oncologica, 44(4), 382-388. http://dx.doi.org/10.1080/02841860510029789

Lindahl-Norberg, A., Lindblad, F., \& Boman, K. K. (2006). Support seeking, perceived support, and anxiety in mothers and fathers after children,s cancer treatment. Psycho-Oncology, 15(4), 335-343. http://dx.doi.org/ $10.1002 /$ pon. 960

O'Reilly, P. (1988). Methodological issues in social support and social network research. Journal of Social Science and Medicine, 26, 861-873. http://dx.doi.org/ 10.1016/0277-9536(88)90179-7.

Phipps, S., Larson, S., Long, A., \& Rai, S. N. (2006). Adaptive Style and Symptoms of Posttraumatic Stress in Children with Cancer and Their Parents. Journal of Pediatric Psychology, 31(3), 298-309. http//dx.doi.org/10,1093/jpepsy/jsj033

Polit, D. F., Beck, C. T., \& Hungler, B. P. (2005). Essentials of Nursing Research (5th ed.). Lippincott: Williams \& Wilkins.

Salovey, P., Detweiler, J. B., Steward, W. T., \& Rothman, A. J. (2000). Emotional states and physical health. Journal of American Psychologist, 55, 110-121. http://dx.doi.org/10.1037//0003-066X.55.1.110

Santacroce, S. (2002). Uncertainty, anxiety and symptoms of posttraumatic stress in parents of children recently diagnosed with cancer. Journal of Pediatric Oncology Nursing, 19(3), 104-111. http://dx.doi.org/10.1053/jpon.2002.123451

Sarason, B. R., Shearin, E. N., Pierce, G. R., \& Sarason, I. G. (1987). Interrelations of social support measures: Theoretical and practical implications. Journal of Personality and Social Psychology, 52(4), 813-312. http://dx.doi.org/10.1037/0022-3514.52.4.813 
Sarhan, W., Khateeb, J., \& Habashneh, M. (2001). Behaviors Depression (1st ed.). Majdalawi.

Scott, E. (2009). Stress relievers for all types of people. Retieved from http://www.managingstress.com

Siegel, R., Naishadham, D., \& Jemal, A. (2013). Cancer Statistics. Journal for Clinicians, 63(1), 11-30. http://dx.doi.org/10.3322/caac.21166

Sloper, P. (2000). Predictors of distress in parents of children with cancer: A prospective study. Journal of Pediatric Psychology, 25, 79-91. http://dx.doi.org/10.1093/jpepsy/25.2.79

Speechley, K. N., \& Noh, S. (1992). Surviving childhood cancer, social support, and parents' psychological adjustment. Journal of Pediatic Psychology, 17(1), 15-31.

Tatjana, K., Nada, K., Jovanka, K., \& Natasa, K. (2012). Importance of Psychological Support for Families of Children with Cancer. Medical review, 65(5/6), 223-227. http://dx.doi.org/10. 2298/MPNSI206223K

Wikipedia, the free encyclopedia. (2009). Stress. Internet. Retrieved from http://en.wikipedia.org/wiki/Stress_(biological)

\section{Appendix}

Appendix A. Participant's Reaction Index.

Please answer the following questions that relate to your experience with each component of the social support program which you chose to participate with it. When answering the questions please select and write down out of $100 \%$ the response that best reflects your opinion and view on the value of the program component to you during the period of your child admission.

\begin{tabular}{|c|c|c|}
\hline & How do you rate the? & \\
\hline 1 & $\begin{array}{l}\text { Stress assessment survey using } \\
\text { Arabic-Language Modified Version of Beck } \\
\text { Depression Inventory. Phase } 1 \text { (Pre program) }\end{array}$ & .........100\% \\
\hline \multirow[t]{6}{*}{2} & Brochure & \\
\hline & - Introduction & $\ldots \ldots 100 \%$ \\
\hline & - Stress management strategies & ...........100\% \\
\hline & - Social Support and it's types & $0 \ldots \ldots \ldots \ldots \ldots \ldots$ \\
\hline & - Referral process outline & $\ldots \ldots \ldots 100 \%$ \\
\hline & - Community resources list & 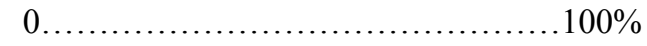 \\
\hline \multirow[t]{4}{*}{3} & Meeting & \\
\hline & - Introduction & $0 \ldots \ldots \ldots \ldots \ldots \ldots \ldots \ldots \ldots \ldots \ldots \ldots \ldots \ldots 100 \%$ \\
\hline & - Discussing challenges & 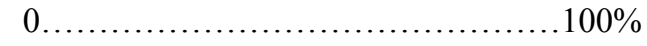 \\
\hline & - Demonstrating stress management strategies & 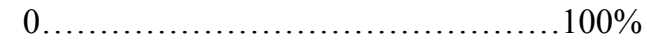 \\
\hline 4 & $\begin{array}{l}\text { Help provided by the nursing students } \\
\text { (Taking care of your child while you leave to } \\
\text { your home) as an example }\end{array}$ & $0 \ldots \ldots \ldots \ldots \ldots \ldots$ \\
\hline 5 & $\begin{array}{l}\text { Stress assessment survey using } \\
\text { Arabic-Language Modified Version of Beck } \\
\text { Depression Inventory. Phase } 2 \text { (Post program) }\end{array}$ & 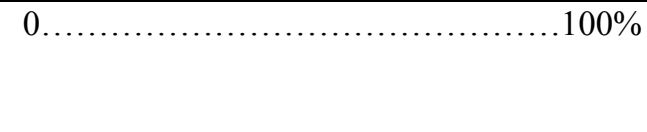 \\
\hline 6 & $\begin{array}{l}\text { Reaction index ( The survey you are filling } \\
\text { now) }\end{array}$ & 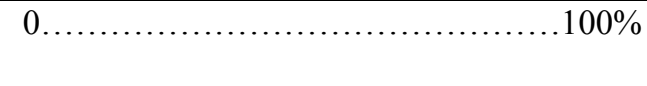 \\
\hline 7 & Program Coordinator Approach & $\ldots .100 \%$ \\
\hline 8 & Please add your comments on the program & $0 \ldots \ldots \ldots \ldots \ldots \ldots \ldots \ldots \ldots$ \\
\hline
\end{tabular}


Appendix B. Meeting format

\begin{tabular}{|c|c|c|c|}
\hline $\begin{array}{l}\text { Time/ } \\
\text { minutes }\end{array}$ & & Content & $\begin{array}{l}\text { Coordinator and } \\
\text { facilitators }\end{array}$ \\
\hline $0-10$ & Introduction & $\begin{array}{l}\text { Introduction of the group coordinator, participants, and } \\
\text { the program objectives and format. }\end{array}$ & $\begin{array}{l}\text { Researcher } \\
\text { (faculty member) }\end{array}$ \\
\hline $10-20$ & $\begin{array}{l}\text { Discussing } \\
\text { challenge }\end{array}$ & $\begin{array}{l}\text { One of the participant mothers choose a significant } \\
\text { situation associated with negative emotions. } \\
\text { Participants as a group discuss alternative about the } \\
\text { situation and how it could be handled. }\end{array}$ & Researcher \\
\hline $20-40$ & $\begin{array}{l}\text { Discussing and } \\
\text { practicing } \\
\text { stress } \\
\text { Management } \\
\text { strategies }\end{array}$ & $\begin{array}{l}\text { Mothers asked to identify the most functional strategies } \\
\text { that they have used to manage the discussed } \\
\text { challenge(s). Stress management strategies mentioned } \\
\text { in the initiative brochure introduced and practiced as } \\
\text { additional suggested strategies, followed by summary } \\
\text { of the meeting. }\end{array}$ & Researcher \\
\hline $40-60$ & Individual plan & $\begin{array}{l}\text { Instrumental type of support in term of money, time and } \\
\text { in-kind assistance were discussed and provided } \\
\text { individually. }\end{array}$ & $\begin{array}{l}\text { Researcher supported by } \\
\text { the assigned nurse } \\
\text { preceptor's and the } \\
\text { assigned nursing } \\
\text { student's. }\end{array}$ \\
\hline
\end{tabular}

